\title{
The c-fos transcript is targeted for rapid decay by two distinct mRNA degradation pathways
}

\author{
Ann-Bin Shyu, Michael E. Greenberg, and Joel G. Belasco \\ Department of Microbiology and Molecular Genetics, Harvard Medical School, Boston, Massachusetts 02115 USA
}

\begin{abstract}
Rapid degradation of c-fos proto-oncogene mRNA is crucial for transient c-fos gene expression. Experiments were performed to investigate the cellular mechanisms responsible for the extremely short half-life of human c-fos mRNA in growth-factor-stimulated fibroblasts. These experiments demonstrate the existence of two distinct cellular pathways for rapid c-fos mRNA degradation. Each of these pathways recognizes a different, functionally independent instability determinant within the c-fos transcript. One instability determinant, which is located within the c-fos $3^{\prime}$-untranslated region, is a 75-nucleotide AU-rich segment. Insertion of this element into $\beta$-globin mRNA markedly reduces the half-life of that normally long-lived message. Nevertheless, specific deletion of the AU-rich element from c-fos mRNA has little effect on the transcript's cytoplasmic halflife due to the presence of the other c-fos instability determinant, which is located in the protein-coding segment of the c-fos message. Examination of mRNA decay in cells treated with transcription inhibitors indicates that one c-fos mRNA degradation pathway is dependent on RNA synthesis, whereas the other is not.
\end{abstract}

[Key Words: mRNA degradation; c-fos; AU-rich element; proto-oncogene]

Received October 28, 1988; revised version accepted November 30, 1988.

An important mechanism for regulating gene expression in all organisms is control of the cytoplasmic concentration of individual gene transcripts. mRNA levels often change dramatically during cell growth and differentiation as a result of changes in transcription, RNA processing, and mRNA decay. Although a great deal has been learned in recent years about the regulation of mRNA synthesis, much less is known about the cellular mechanisms that control mRNA degradation. Nevertheless, a number of studies have revealed that bacterial and mammalian gene expression can be modulated through changes in mRNA stability (for reviews, see Belasco and Higgins 1988; Brawerman 1987).

In mammalian cells, a class of 10-50 growth-factorinducible genes has been identified whose transcripts appear transiently in the cytoplasm immediately after stimulation with growth factors/Greenberg and Ziff 1984; Lau and Nathans 1985; Lim et al. 1987; Almendral et al. 1988). The transient expression of these genes is a consequence not only of the brevity of their transcription but also of their transcripts' very short lifetime in the cytoplasm. The lability of this class of mRNA, which decays with a half-life of $<30 \mathrm{~min}$, distinguishes it from most mammalian messages, which typically are much more stable, with half-lives ranging from hours to days (Krowczynska et al. 1985). As yet, little is understood about the mechanisms by which these growthfactor-inducible transcripts are degraded.

The best characterized of the growth-factor-inducible messages is the transcript of the c-fos proto-oncogene.
The c-fos gene encodes a nuclear protein that forms a complex with the mammalian transcription factor AP-1 and is believed to regulate the transcription of a diverse set of genes important for cell growth and differentiation (Chiu et al. 1988; Rauscher et al. 1988; Sassone-Corsi et al. 1988). Expression of the c-fos gene is induced rapidly and transiently in a wide range of mammalian cell types by growth factors, phorbol esters, neurotransmitters, and membrane-depolarizing agents/Greenberg and Ziff 1984; Curran and Morgan 1985, 1986; Greenberg et al. $1985,1986 \mathrm{~b}$ ). Induction of c-fos occurs at the transcriptional level and is independent of new protein synthesis (Cochran et al. 1984; Greenberg et al. 1986a). Minutes after its activation, transcription of c-fos ceases /Greenberg et al. 1985, 1986b). The newly synthesized c-fos mRNA is transported to the cytoplasm, where it is translated for only a brief period of time before being degraded rapidly (Kruijer et al. 1984; Muller et al. 1984). This transient accumulation of c-fos mRNA appears to be critical to normal cellular function because mutations that result in its deregulated expression can lead to oncogenic transformation (Miller et al. 1984; Meijlink et al. 1985; Jenuwein and Muller 1987).

There has been considerable interest in understanding the molecular basis for the rapid turnover of $\mathrm{c}$-fos mRNA. Initial experiments showed that substitution of heterologous RNA for the $3^{\prime}$ half of the c-fos transcript can have a stabilizing effect (Treisman 1985). The c-fos 3 '-untranslated region (UTR) contains an AU-rich element (ARE, Fig. 1) that resembles an RNA segment pre- 


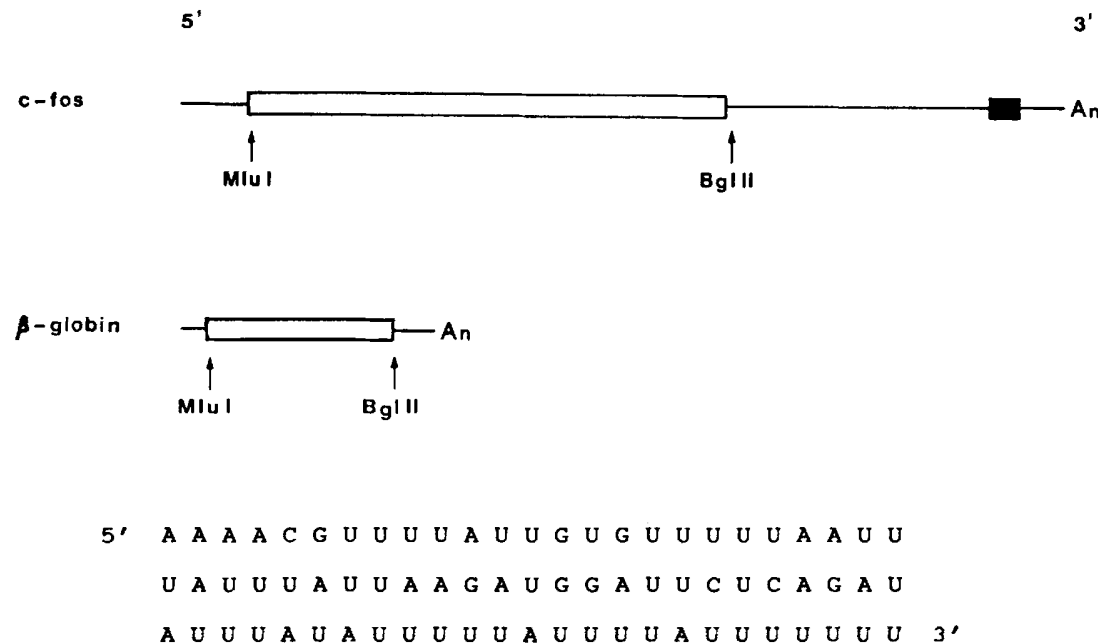

3' Figure 1. The c-fos and $\beta$-globin transcripts. (Top) Diagrams of c-fos and $\beta$-globin mRNA. (Thin lines) 5'- and 3'-UTRs; (open rectangles) protein-coding regions; (solid rectangle) ARE; $\left(A_{n}\right) 3^{\prime}$ poly(A) tail. Arrows mark sites that correspond to DNA restriction sites used in the construction of $\mathrm{c}$-fos/ $\beta$-globin gene fusions. (MluI) A restriction site created in the $c$-fos and $\beta$-globin genes by three point mutations near the boundary between the 5 'UTR and the protein-coding region; (BgIII) a restriction site that is located immediately downstream of the rabbit $\beta$-globin translation termination codon and that was introduced into the c-fos gene by linker insertion at an NaeI site near the beginning of the c-fos 3'. UTR. (Bottom) Sequence of the 75-nucleotide ARE of human c-fos mRNA. viously implicated in the lability of granulocyte-monocyte colony-stimulating factor (GM-CSF) mRNA (van Straaten et al. 1983; Shaw and Kamen 1986). Large deletions in the c-fos $3^{\prime}$-UTR that remove the ARE appear to retard c-fos mRNA degradation in actively growing fibroblasts when the c-fos gene is constitutively transcribed from a heterologous promoter and decay is monitored in the presence of the transcription inhibitor actinomycin D (Fort et al. 1987; Rahmsdorf et al. 1987). Nevertheless, the role of the ARE in determining the half-life of c-fos mRNA under normal conditions of transient gene expression in growth-factor-stimulated cells has not been established.

Here, we report experiments that reveal the existence of two distinct cellular pathways for rapid c-fos mRNA degradation. Each of these pathways recognizes a different c-fos instability determinant, either of which is sufficient to render the c-fos message highly labile. One of the instability determinants is the ARE in the $3^{\prime}$ UTR; the other is a novel element within the c-fos protein-coding region. Remarkably, deletion of the ARE alone has little effect on c-fos mRNA instability in growth-factor-stimulated fibroblasts. We hypothesize that mammalian cells have evolved multiple c-fos mRNA decay mechanisms to ensure that this transcript is degraded rapidly within minutes after it is synthesized.

\section{Results}

Synthesis and decay of human c-fos mRNA in NIH-3T3 cells

To identify determinants responsible for the marked lability of c-fos mRNA, a transient-induction assay was employed to monitor the decay of human c-fos mRNA in mouse fibroblasts after growth-factor stimulation. A wild-type genomic clone of the human c-fos gene (pF711) was introduced into mouse NIH-3T3 cells by transient transfection. After serum starvation for 25-30 hr, c-fos transcription was induced transiently by stimulation with fetal calf serum, and total cytoplasmic RNA was isolated at time intervals. The relative concentrations of human c-fos mRNA, mouse c-fos mRNA, and $\alpha$-globin mRNA (a cotransfected internal standard) at various times after serum stimulation were then determined by RNase-protection analysis of equal amounts of each RNA sample, using a mixture of uniformly radiolabeled RNA probes (Fig. 2, top).

Transcription of both the transfected human c-fos gene and the endogenous mouse c-fos gene was stimulated transiently by serum addition, and these two messages decayed with similar kinetics (half-lives of $15 \pm 3$ min and $16 \pm 1 \mathrm{~min}$, respectively; Fig. 2, top/following the spontaneous cessation of $c$-fos transcription that occurred within $1 \mathrm{hr}$ after serum induction /Greenberg and Ziff 1984; Greenberg et al. 1985). Efficient degradation of the human message required transfection with no more than $5 \mu \mathrm{g}$ of pF711 per plate of $2 \times 10^{6}$ cells; transfection with $20 \mu \mathrm{g}$ of $\mathrm{pF} 711$ per plate increased the apparent half-life of this transcript to $90-100 \mathrm{~min}$, possibly by saturating the cellular machinery involved in c-fos mRNA degradation. $\alpha$-Globin mRNA, which was synthesized constitutively under the control of an SV40 enhancer and did not decay detectably over the time course of these experiments, served as an internal control that allowed correction for small variations in transfection efficiency and sample handling.

These findings show that the decay of human c-fos mRNA and endogenous mouse c-fos mRNA can be studied in parallel in transiently transfected NIH-3T3 cells under conditions that are physiologically relevant to normal c-fos gene expression and without the use of drugs to inhibit transcription.

The $c$-fos $3^{\prime}$-UTR is not required for $c$-fos $m R N A$ instability

Experiments in other laboratories with c-fos genes transcribed from heterologous promoters have implicated an AU-rich segment of the c-fos $3^{\prime}$-UTR (Fig. 1) in causing c-fos mRNA instability (Fort et al. 1987; Rahmsdorf et al. 1987). To test whether the ARE is necessary for the short cytoplasmic half-life of the c-fos transcript after 


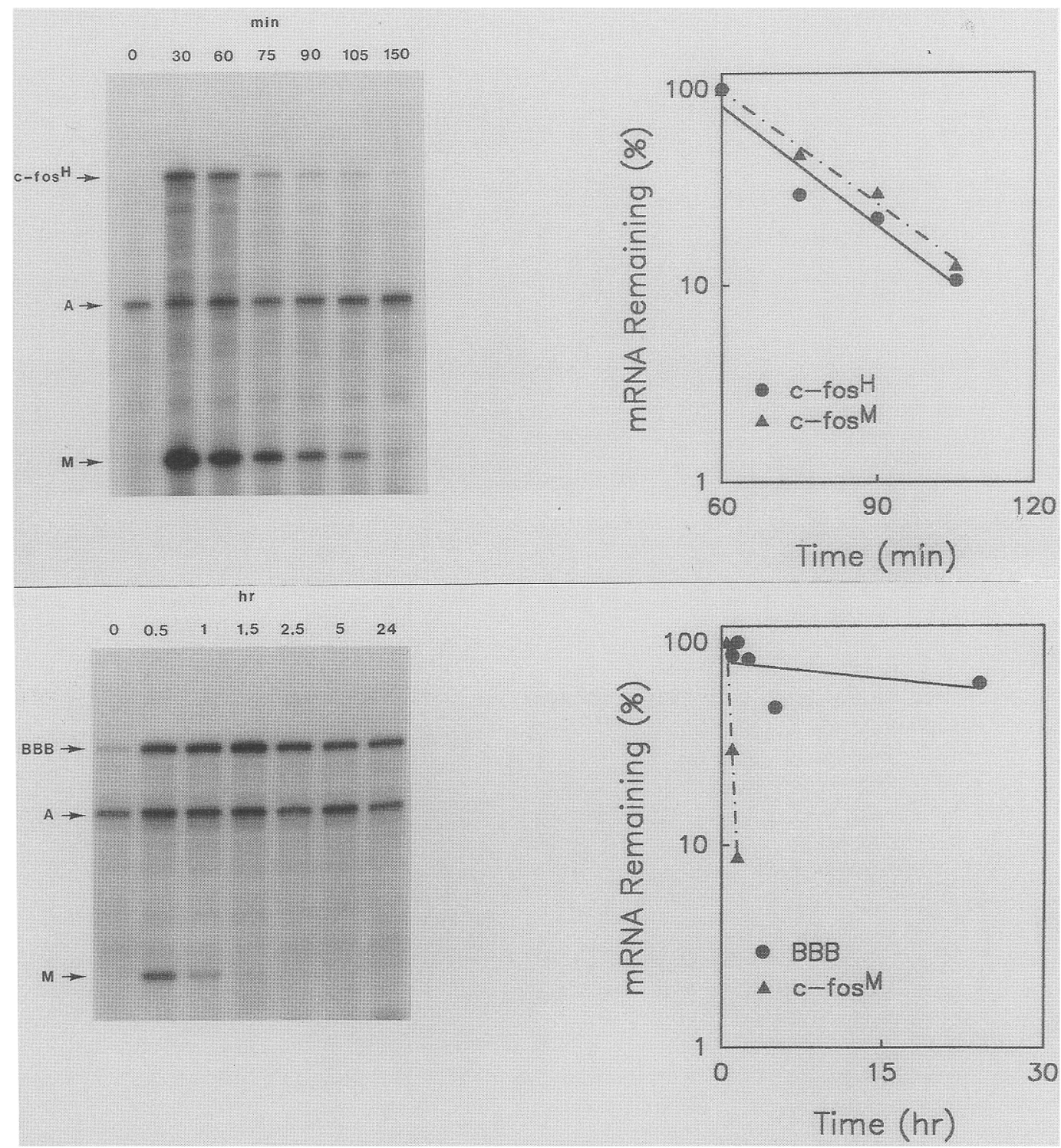

Figure 2. Induction and decay of human c-fos mRNA and rabbit $\beta$-globin mRNA. NIH-3T3 cells were transiently transfected with pSVol and either pF711 (top) or pBBB (bottom). Total cytoplasmic RNA was isolated at time intervals after serum stimulation and analyzed by RNase protection and gel electrophoresis. (c-fos ${ }^{\mathrm{H}}$ ) pSP6fos-derived probe fragment protected by human c-fos mRNA; (BBB) pT7BG-derived probe fragment protected by BBB mRNA; (M) pSP6fos-derived probe fragment protected by mouse c-fos mRNA; (A) pSP6a133-derived probe fragment protected by $\alpha$-globin mRNA. Times correspond to minutes (top) or hours (bottom) after serum stimulation. Beside each autoradiogram is a semilogarithmic plot of the decay of human $\mathrm{c}$-fos $\left(\mathrm{c}-\mathrm{fos}^{\mathrm{H}}\right)$ or rabbit $\beta$-globin (BBB) mRNA (solid line) and mouse c-fos mRNA (c-fos ${ }^{\mathrm{M}}$, dashed/dotted line).

growth-factor stimulation, a deletion was introduced into the human c-fos gene that precisely removed this 75-bp element (Table 1). The cytoplasmic half-life of the transcript of the resulting c-fos allele (F $\Delta 1$ ) was then determined after serum induction of transiently transfected NIH-3T3 fibroblasts. Surprisingly, the half-life of this message was found to be only $20 \pm 3 \mathrm{~min}$ (Fig. 3, topl, a value very similar to that measured for wild-type c-fos mRNA (15 $\pm 3 \mathrm{~min})$. This finding demonstrates that the c-fos ARE is not required for the instability of c-fos mRNA in serum-stimulated fibroblasts.

To test for other structures in the long c-fos $3^{\prime}$-UTR that might contribute to $c$-fos mRNA lability, a nested set of deletions was created within this region. These deletions removed the ARE in the c-fos $3^{\prime}$-UTR and extended unidirectionally for various distances (56-574 bp) upstream from it (F $\Delta 2-F \Delta 6$, Table 1). The cytoplasmic half-lives of the transcripts of the resulting $\mathrm{c}$-fos alleles were measured as before, and all were found to decay at about the same rate as wild-type c-fos mRNA (Fig. 3, bottom; Table 1). The transcript of an additional c-fos deletion mutant (F $\Delta 7$; Table 1) that lacked a 201nucleotide segment immediately upstream of the polyadenylylation signal (AAUAAA), including the ARE, also decayed with a short half-life of $15 \pm 1 \mathrm{~min}$. Taken together, these findings demonstrate that no single ele- 
Table 1. Half-lives of $\mathrm{c}$-fos transcripts with deletions in the $3^{\prime}-U T R$

\begin{tabular}{ccc}
\hline Deletion mutant & $\begin{array}{l}\text { Deletion end } \\
\text { points }(\mathrm{kb})^{\mathrm{a}}\end{array}$ & $\begin{array}{l}\text { Half-life } \\
\text { (min) }\end{array}$ \\
\hline Wild-type & - & $15 \pm 3$ \\
F $\Delta 1$ & $1.92-2.00$ & $20 \pm 3$ \\
F $\Delta 2$ & $1.87-2.00$ & $18 \pm 4$ \\
F $\Delta 3$ & $1.67-2.00$ & $15 \pm 4$ \\
F $\Delta 4$ & $1.60-2.00$ & $20 \pm 2$ \\
F $\Delta 5$ & $1.51-2.00$ & $21 \pm 1$ \\
F $\Delta 6$ & $1.35-2.00$ & $18 \pm 1$ \\
F $\Delta 7$ & $1.87-2.07$ & $15 \pm 1$ \\
\hline
\end{tabular}

and points are measured in kilobases from the $5^{\prime}$ terminus of human c-fos mRNA. In the wild-type c-fos message, the $5^{\prime}$ UTR extends from nucleotide 1 to 155 , the protein-coding region from 156 to 1295 , and the 3'-UTR from 1296 to 2104 . The c-fos ARE is located between positions 1920 and 1994.

ment $>30-50$ nucleotides from either end of the 809 nucleotide $3^{\prime}$-UTR of c-fos mRNA, including the AUrich element, is necessary for c-fos mRNA instability.

The 3'-UTR deletions described above left intact the RNA segment between the polyadenylylation signal and the site of poly(A) addition. To test whether this segment contains an instability determinant, we replaced all but the first 27 nucleotides of the c-fos $3^{\prime}$-UTR with the $3^{\prime}$-UTR of the rabbit $\beta$-globin message. As shown below, rabbit $\beta$-globin mRNA is very stable in serumstimulated fibroblasts. The resulting hybrid transcript, which should be properly polyadenylylated at the $\beta$ globin poly(A) site, was designated FFB. This name indicates that the $5^{\prime}$-UTR and the coding region were derived from the human c-fos message, whereas the $3^{\prime}$ UTR was derived from rabbit $\beta$-globin mRNA. In this three-letter nomenclature for gene fusions transcribed under the control of the c-fos promoter, the first letter refers to the origin of the $5^{\prime}$-UTR (F if from human c-fos and $B$ if from rabbit $\beta$-globin|, the second letter indicates the source of the coding region, and the third letter refers to the source of the $3^{\prime}-$ UTR. When the FFB gene was introduced into NIH-3T3 cells by transient transfection, cytoplasmic half-life of its transcript after serum induction was found to be only $21 \pm 1 \mathrm{~min}$ (Fig. 4, top), about the same as that of wild-type c-fos mRNA. The instability of this c-fos mRNA variant, which lacked nearly the entire c-fos $3^{\prime}$-UTR, confirmed that the c-fos $3^{\prime}$-UTR is not necessary for c-fos mRNA instability.

Insertion of the c-fos ARE can destabilize an otherwise long-lived message

The lability of c-fos mRNA lacking the $3^{\prime}$-UTR could be explained in either of two ways. One possibility is that the c-fos 3'-UTR does not contain a signal for rapid mRNA degradation. Alternatively, there may be a determinant of mRNA instability in the 3'-UTR (e.g., the ARE) that is dispensable because of the presence of one or more additional instability determinants located up- stream of the $3^{\prime}$-UTR. This additional element would ensure rapid decay of c-fos mRNA even when the $3^{\prime}$ UTR is absent. To ascertain whether the c-fos 3'-UTR, coding region, and 5'-UTR contain determinants of mRNA instability, we decided to substitute each of these c-fos mRNA segments for the corresponding segment of the stable rabbit $\beta$-globin transcript and to measure the decay rate of the resulting hybrid messages (BBF, BFB, and FBB).

As a first step, a c-fos/ $\beta$-globin gene fusion was constructed in which the $\beta$-globin promoter had been replaced precisely with the serum-inducible c-fos promoter. This gene fusion was designated BBB to indicate that it encoded a wild-type rabbit $\beta$-globin transcript whose $5^{\prime}$ end mapped to the normal cap site. Induction and decay of $\beta$-globin mRNA transcribed from the $c$-fos promoter was then monitored in transfected NIH-3T3 cells to learn whether fusion of the c-fos promoter to a heterologous gene would allow transient transcription of that gene in response to serum stimulation. As in the case of the c-fos gene, BBB transcription was induced rapidly by addition of serum (Fig. 2, bottom). However, unlike c-fos mRNA, which disappears rapidly from the cytoplasm after cessation of transcription (Fig. 2, top), the cytoplasmic concentration of $\beta$-globin mRNA transcribed from the c-fos promoter reached a plateau within $\mathrm{l} \mathrm{hr}$ after serum stimulation and did not decline significantly for at least $24 \mathrm{hr}$ thereafter. These findings indicate that the c-fos promoter can direct transient synthesis of $\beta$-globin mRNA in response to serum stimulation and that the half-life of $\beta$-globin mRNA in serum-stimulated cells is very long $(>24 \mathrm{hr})$.

To test whether the c-fos $3^{\prime}$-UTR contains a determinant of mRNA instability, we next analyzed the decay of a hybrid message (BBF) in which the 3'-UTR of $\beta$-globin mRNA was replaced with the corresponding segment of the c-fos transcript. As in the case of the BBB gene, transcription of the $\mathrm{BBF}$ gene was directed by the c-fos promoter. The cytoplasmic half-life of the chimeric BBF transcript was only $28 \pm 2 \mathrm{~min}$ (Fig. 4, bottom), a value almost as short as that of c-fos mRNA itself and $<2 \%$ as long as that of wild-type $\beta$-globin (BBB) mRNA. Thus, although deletion of the c-fos $3^{\prime}$-UTR does not stabilize c-fos mRNA, this mRNA segment is able to confer a high degree of instability upon the otherwise long-lived $\beta$-globin message.

Further analysis showed that the functional element primarily responsible for the instability of BBF mRNA was the AU-rich segment within the c-fos $3^{\prime}$-UTR. Precise deletion of the 75-nucleotide c-fos ARE from BBF stabilized the message considerably (BBF $\triangle A R E$; Fig. 5, top). Moreover, simple insertion of the c-fos ARE into the $3^{\prime}$-UTR of an otherwise intact $\beta$-globin message /to generate $\mathrm{BBB}+\mathrm{ARE}$ / was highly destabilizing; this insertion reduced the half-life of $\beta$-globin mRNA from $>24 \mathrm{hr}$ to only $37 \pm 6 \mathrm{~min}$ (Fig. 5 , bottom).

Taken together, these findings indicate that the c-fos ARE functions as an mRNA-destabilizing element. However, because deletion of the ARE or the entire 3'UTR fails to stabilize c-fos mRNA, it appears that the c-fos message contains one or more additional deter- 


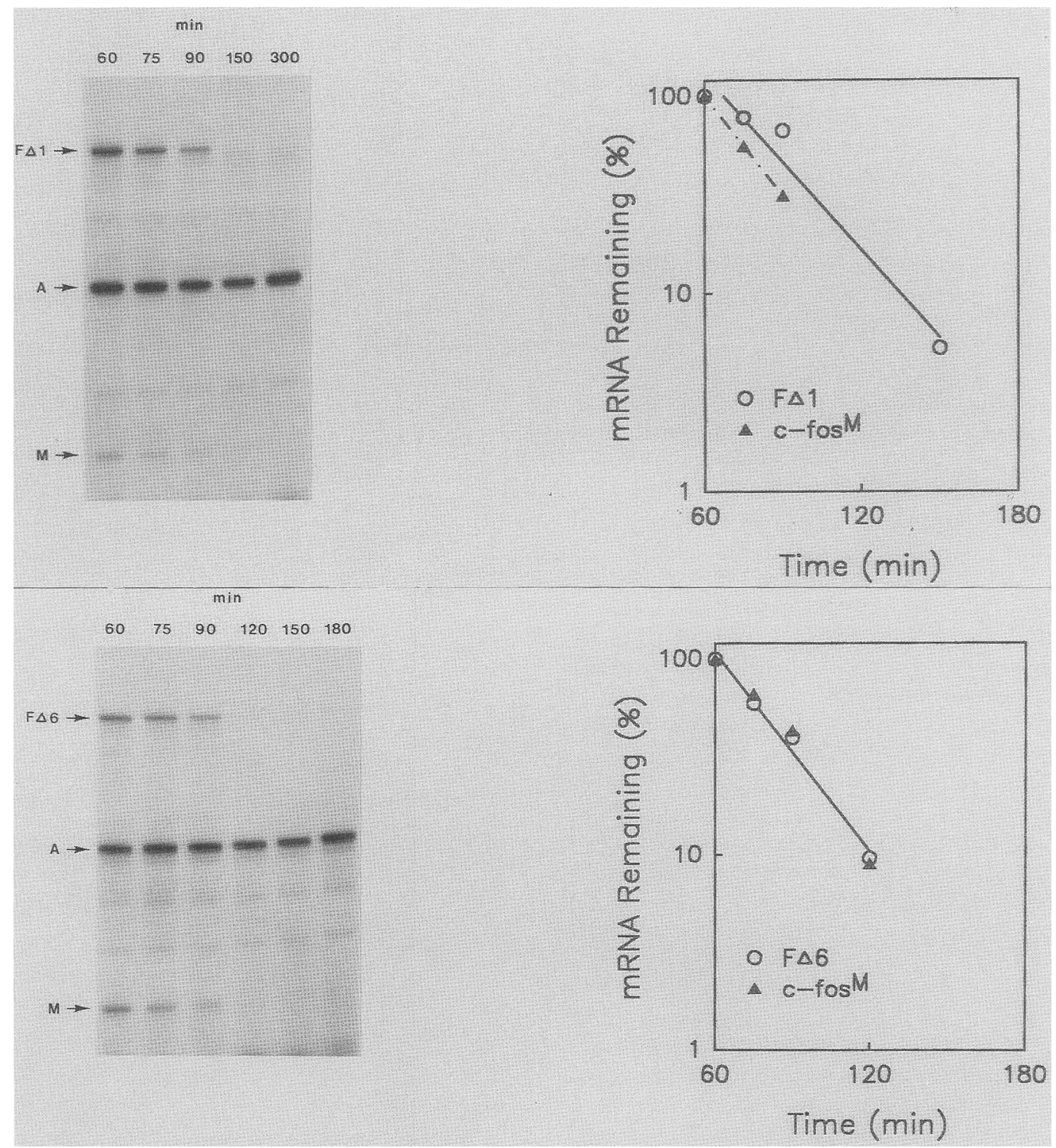

Figure 3. Decay of human c-fos mRNA with deletions in the $3^{\prime}$-UTR. NIH-3T3 cells were transiently transfected with pSV $\alpha 1$ and either pF $\Delta \mathrm{l}$ (top) or pF $\Delta 6$ (bottom). Total cytoplasmic RNA was isolated at time intervals after serum stimulation and analyzed by RNase protection and gel electrophoresis. (F $\Delta 1$ ) pSP6fos-derived probe fragment protected by F $\Delta 1$ mRNA; (F $\Delta 6$ ) pSP6fos-derived probe fragment protected by F 6 mRNA; (M) pSP6fos-derived probe fragment protected by mouse c-fos mRNA; (A) pSP6a133-derived probe fragment protected by $\alpha$-globin mRNA. Times correspond to minutes after serum stimulation. Beside each autoradiogram is a semilogarithmic plot of the decay of $\mathrm{F} \Delta \mathrm{l}$ or F $6 \mathrm{mRNA}$ (solid line) and mouse c-fos mRNA (c-fos ${ }^{\mathrm{M}}$, dashed/dotted line)

minants of instability in the $5^{\prime}$-UTR or in the coding region.

The $c$-fos coding region contains a determinant of mRNA instability

To map the location of the additional determinant(s) of c-fos mRNA instability, gene fusions were constructed in which the $\beta$-globin coding region or $5^{\prime}$-UTR was replaced with the corresponding segment of the c-fos gene (BFB and FBB). The construction of these gene fusions was facilitated by the introduction of point mutations into plasmid clones of the c-fos and $\beta$-globin genes that resulted in the creation of a unique MluI restriction site $5 \mathrm{bp}$ downstream of the ATG translation initiation codon of each gene. These point mutations per se did not affect the half-life of the $\beta$-globin message (A.-B. Shyu, unpubl.). Transcription of each gene fusion was directed by the c-fos promoter and could be transiently induced by serum stimulation.

Replacement of the $\beta$-globin coding region with that of $\mathrm{c}$-fos (BFB) had a dramatic destabilizing effect: BFB mRNA decayed with a half-life of only $17 \pm 2 \mathrm{~min}$ (Fig. 6 , top). Thus, like the c-fos $3^{\prime}$-UTR, the c-fos-coding region contains a determinant of mRNA instability that alone is sufficient to destabilize an otherwise long-lived 


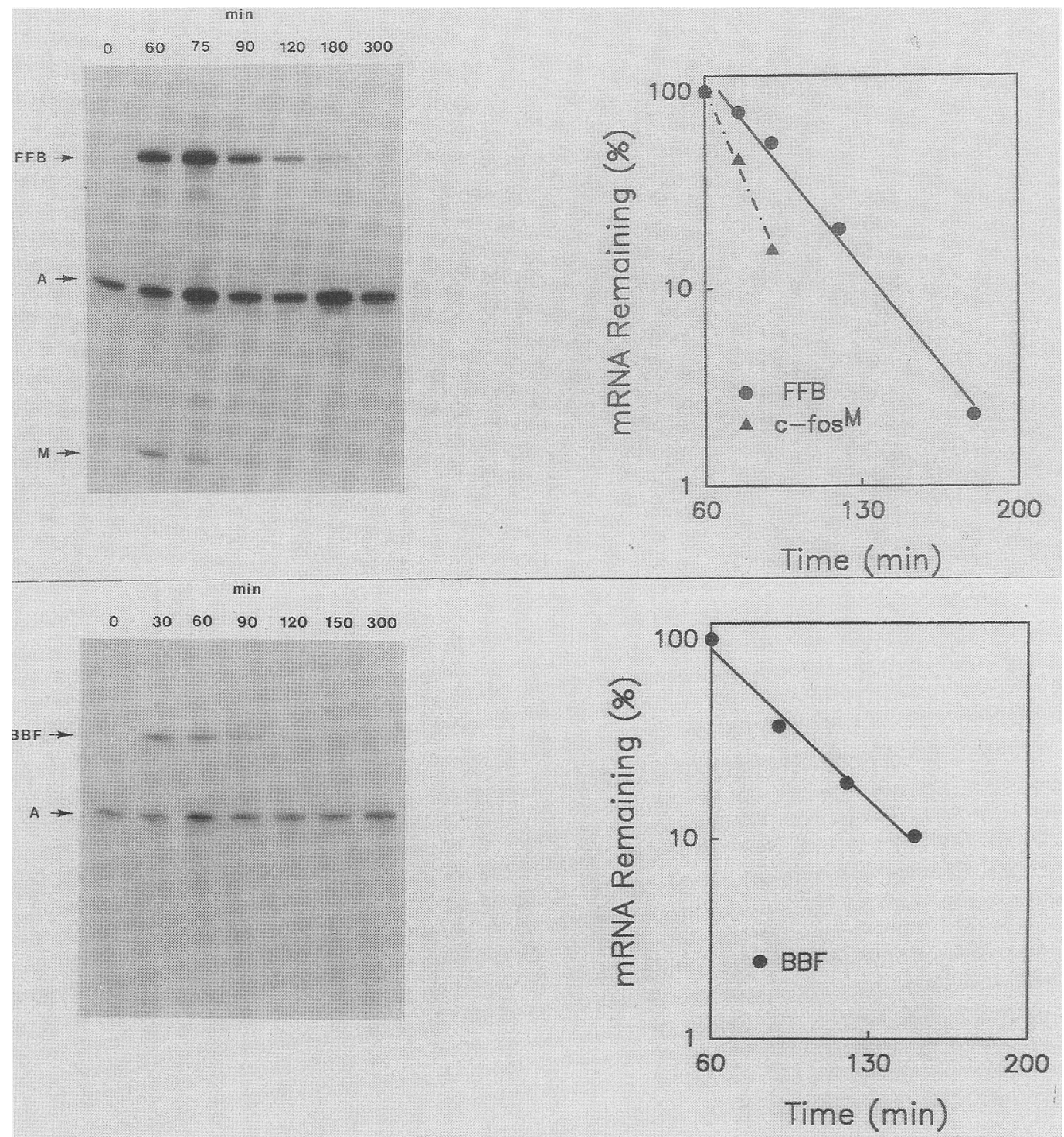

Figure 4. Decay of FFB and BBF mRNA. NIH-3T3 cells were transiently transfected with pSVal and either pFFB (top) or pBBF (bottom). Total cytoplasmic RNA was isolated at time intervals after serum stimulation and analyzed by RNase protection and gel electrophoresis. (FFB) pSP6fos-derived probe fragment protected by FFB mRNA; (BBF) pT7BG-derived probe fragment protected by BBF mRNA; (M) pSP6fos-derived probe fragment protected by mouse c-fos mRNA; (A) pSP6al33-derived probe fragment protected by globin mRNA. Times correspond to minutes after serum stimulation. Beside each autoradiogram is a semilogarithmic plot of the decay of FFB or BBF mRNA (solid line) and mouse c-fos mRNA (c-fos ${ }^{\mathrm{M}}$, dashed/dotted line).

message. The instability determinant within the coding region apparently is more effective at destabilizing mRNA than even the ARE, inasmuch as the BFB transcript decays about twice as fast as BBB + ARE mRNA. In contrast to the $3^{\prime}$-UTR and coding region, substitution of the c-fos $5^{\prime}$-UTR for that of $\beta$-globin (FBB) hardly affected the cytoplasmic stability of the $\beta$-globin transcript, the half-life of FBB mRNA being $>10 \mathrm{hr}$ (Fig. 6, bottom).

\section{Each c-fos instability determinant is the target of a distinct degradation pathway}

To begin to characterize degradation mediated by each of the determinants of c-fos mRNA instability, we ex- amined the effect of actinomycin D on message decay. Actinomycin $\mathrm{D}$ is a transcription inhibitor that acts by intercalating into nucleic acids. Interestingly, we discovered that actinomycin D differentially affects the function of the instability determinants located in the $3^{\prime}$ UTR and the protein-coding region. Treatment of serum-stimulated cells with actinomycin D gradually inhibited degradation of BBF mRNA. Within $0.5 \mathrm{hr}$ after addition of actinomycin $\mathrm{D}$, this message decayed slowly with a half-life of $\sim 110 \mathrm{~min}$, and it ceased to decay altogether within $3 \mathrm{hr}$ (Fig. 7, top). In contrast, actinomycin $D$ treatment had only a small effect on the decay of BFB mRNA, whose half-life was $28 \pm 2 \mathrm{~min}$ in the presence of this drug and did not change with time (Fig. 7, top); nor did actinomycin D significantly affect the half-life of 


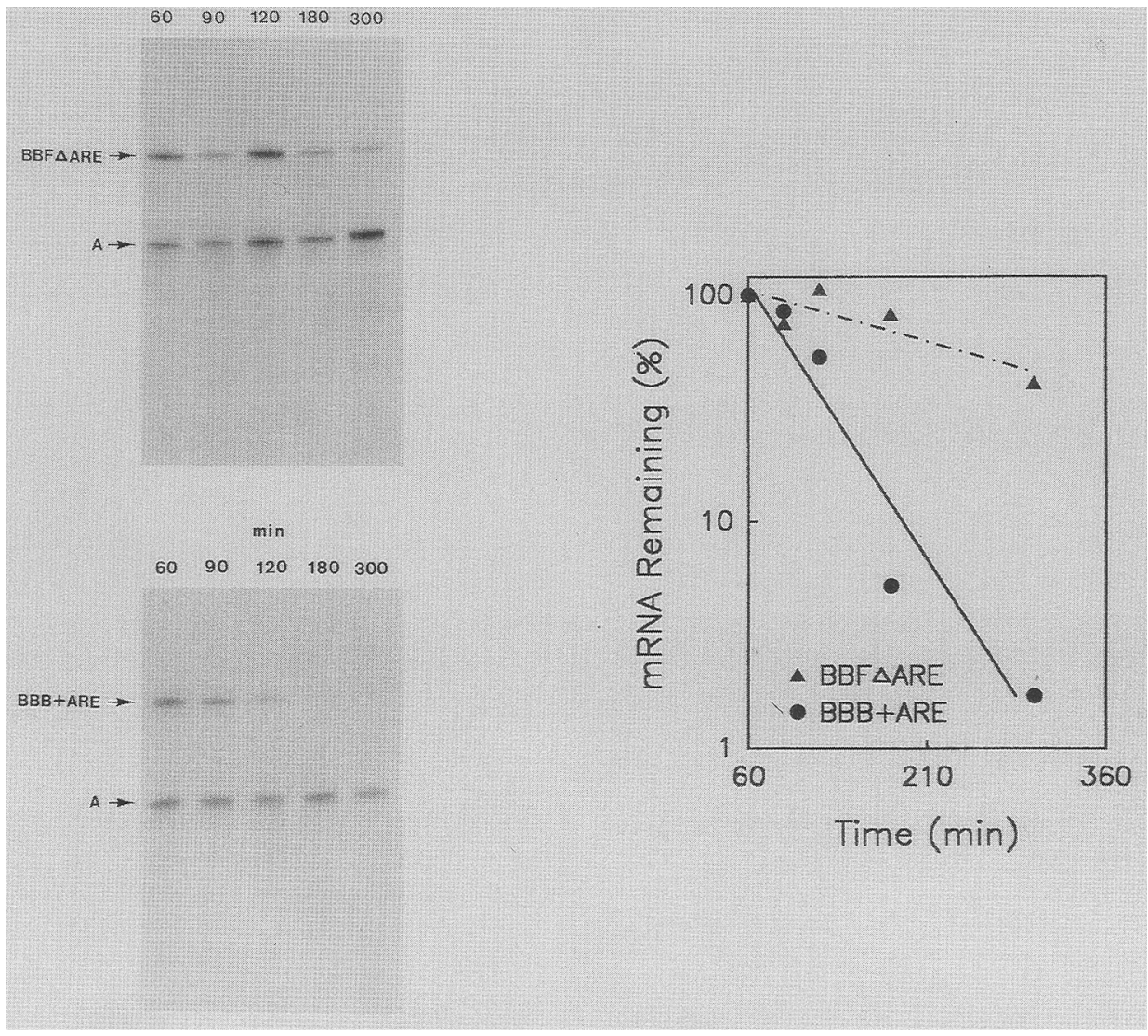

Figure 5. Decay of BBF $\triangle A R E$ and BBB + ARE mRNA. NIH-3T3 cells were transiently transfected with pSV $\alpha 1$ and either pBBF $\triangle A R E$ (top) or pBBB + ARE (bottom). Total cytoplasmic RNA was isolated at time intervals after serum stimulation and analyzed by RNase protection and gel electrophoresis. (BBF $\triangle A R E$ ) pT7BG-derived probe fragment protected by BBF $\triangle A R E$ mRNA; (BBB + ARE) pT7BG-derived probe fragment protected by BBB + ARE mRNA; (A) pSP6 133 -derived probe fragment protected by $\alpha-g l o b i n$ mRNA. Times correspond to minutes after serum stimulation. Beside the autoradiograms is a semilogarithmic plot of the decay of BBF $\triangle A R E$ mRNA (dashed/dotted line) and BBB + ARE mRNA (solid line).

the endogenous mouse c-fos message. These findings indicate that in serum-stimulated fibroblasts, actinomycin $D$ inhibits decay mediated by the c-fos ARE but has little effect on degradation involving the instability determinant(s) present in the c-fos protein-coding region. This differential inhibition may be evidence that the ARE and the c-fos coding-region determinant are targets of two distinct cellular pathways for mRNA degradation. Alternatively, both determinants might be targeted by the same degradation pathway, and actinomycin D might inhibit ARE-mediated degradation selectively by site-specific intercalation into c-fos mRNA.

To distinguish between these possibilities, we examined the decay of BBF and BFB mRNA after treatment of serum-stimulated cells with 5,6-dichloro-1- $\beta$-D-ribofuranosylbenzimidazole (DRB), a transcription inhibitor that functions by interacting specifically with the RNA polymerase II transcription apparatus rather than by intercalating into DNA (Zandomeni et al. 1982; Maderious and Chen-Kiang 1984). Like actinomycin D, DRB gradually inhibited decay of the BBF transcript but had little effect on the degradation of BFB mRNA, which decayed with a uniform half-life of $25 \pm 4 \mathrm{~min}$ in the presence of DRB (Fig. 7, bottom). Because two transcription inhibitors with different modes of action both have the same differential effect on BBF and BFB mRNA decay, we conclude that the c-fos ARE and the c-foscoding-region determinant direct rapid mRNA degradation by two distinct cellular pathways and that the degradation pathway that targets the ARE is transcription dependent in serum-stimulated cells.

\section{Discussion}

Our findings show for the first time that c-fos mRNA is targeted for rapid degradation by two distinct cellular pathways, each of which recognizes a different instability determinant within the c-fos transcript. One determinant of c-fos mRNA instability is the ARE within the c-fos $3^{\prime}$-UTR (Fig. 1). Insertion of this sequence into the 3'-UTR of $\beta$-globin mRNA reduces the half-life of that message from $>24 \mathrm{hr}$ down to only $37 \mathrm{~min}$. Remarkably, this element is not necessary for c-fos mRNA instability, and its deletion has only a small effect on the half-life of the c-fos transcript.

We have identified a second, functionally independent 


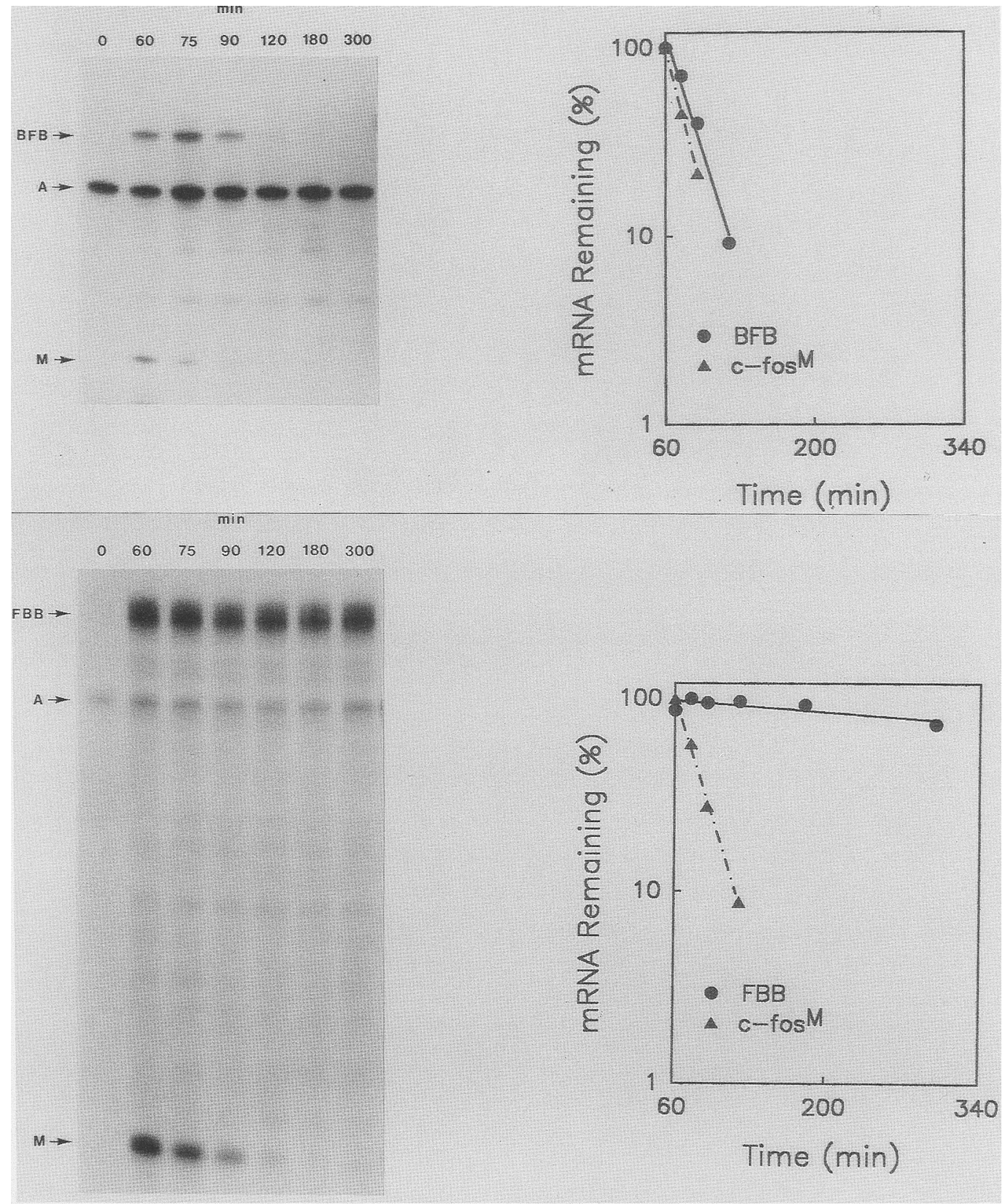

Figure 6. Decay of BFB and FBB mRNA. NIH-3T3 cells were transiently transfected with pSV $\alpha$ l and either pBFB (top) or pFBB (bottom). Total cytoplasmic RNA was isolated at time intervals after serum stimulation and analyzed by RNase protection and gel electrophoresis. (BFB) pSP6BFB-derived probe fragment protected by BFB mRNA; (FBB) pT7BG-derived probe fragment protected by FBB mRNA; (M) pSP6fos-derived probe fragment protected by mouse c-fos mRNA; (A) pSP6 $\alpha 133$-derived probe fragment protected by $\alpha$-globin mRNA. Times correspond to minutes after serum stimulation. Beside each autoradiogram is a semilogarithmic plot of the decay of BFB or FBB mRNA (solid line) and mouse c-fos mRNA (c-fos ${ }^{M}$, dashed/dotted line).

determinant of $\mathrm{c}$-fos mRNA instability within the protein-coding region of the message (Fig. 1). Replacement of the coding region of $\beta$-globin mRNA with the corresponding c-fos segment results in a dramatically reduced half-life of just $17 \mathrm{~min}$. The presence of a destabilizing element in the c-fos protein-coding segment explains why deletion of the ARE or of the entire 3'-UTR has little effect on the decay rate of c-fos mRNA. Indeed, our data suggest that degradation mediated by this coding region determinant is the primary pathway for c-fos mRNA decay. Recently, Kabnick and Housman (1988) have reported corroborating evidence that structural elements outside of the $3^{\prime}$-UTR contribute to c-fos mRNA instability.

Our data indicate that the ARE and the determinant|s| of instability in the c-fos coding region are each the target of a different cellular pathway for mRNA degradation. The c-fos coding region contains neither a long 
Shyu et al.

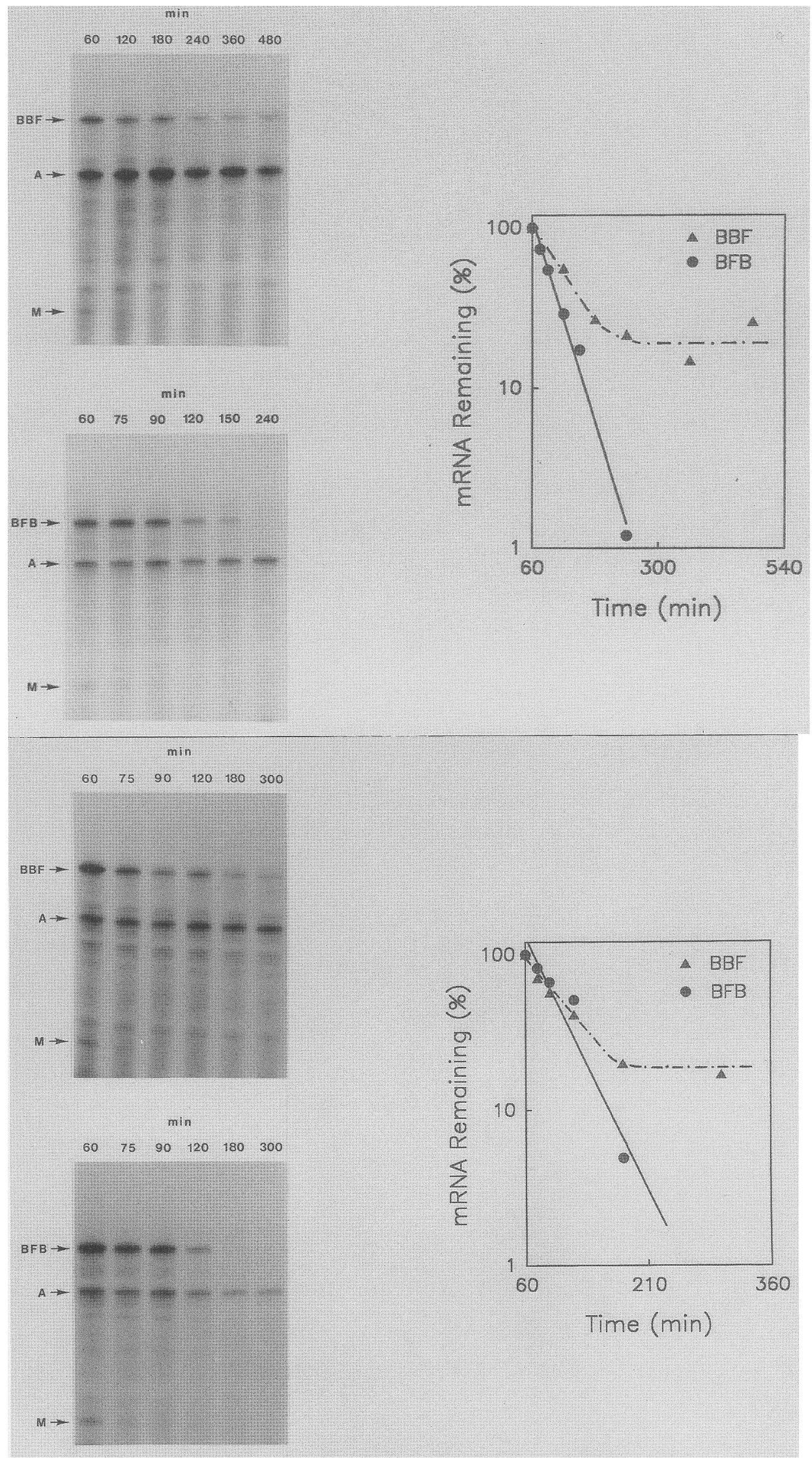

Figure 7. (See facing page for legend). 
AU-rich segment nor the pentanucleotide AUUUA found in all known AREs. Moreover, treatment of serum-stimulated cells with either of two transcription inhibitors (DRB or actinomycin D) gradually blocks degradation mediated by the c-fos ARE but has little effect on the decay pathway for which the c-fos protein-coding region is a target.

Previous studies have shown that the c-fos transcript is stabilized by treatment of cells with translation inhibitors (Greenberg et al. 1986a), which could act by blocking synthesis of a labile protein necessary for c-fos mRNA degradation and/or by disrupting the normal polysomal structure of the c-fos message. Because DRB and actinomycin $\mathrm{D}$ inhibit transcription by entirely different mechanisms and because DRB is not thought to bind RNA, our findings indicate that the ARE-dependent mRNA degradation pathway requires synthesis of a labile gene product whose activity is lost within $3 \mathrm{hr}$ after transcription is blocked. This unstable gene product apparently is not required for the degradation pathway that targets the c-fos coding-region determinant. If this gene product is a protein, it might help to explain the stabilizing effect of translation inhibitors on c-fos mRNA; it would also imply that the message encoding this protein is itself highly labile in serum-stimulated cells, as the effect on protein synthesis of inhibiting synthesis of a stable transcript would not be apparent for many hours.

Our finding that deletion of the c-fos ARE hardly affects the half-life of the human c-fos message differs from previous studies of mouse c-fos mRNA (Fort et al. 1987; Rahmsdorf et al. 1987). In those experiments, the decay rate of the mouse c-fos transcript slowed significantly upon removal of large 3'-UTR segments containing the ARE. The difference between our results and those of others might be explained by the way the experiments were carried out. Previous studies of mouse c-fos mRNA decay used actinomycin $\mathrm{D}$ in actively growing cells to block constitutive transcription of $\mathrm{c}$-fos from a heterologous promoter. In contrast, to ensure physiological conditions relevant to normal c-fos gene expression, our studies have been performed in growth-factor-stimulated cells. Moreover, we have monitored mRNA decay in the absence of transcription inhibitors to avoid the perturbation of mRNA half-life that can occur in cells treated with such inhibitors (see above; Mullner and Kuhn 1988). Finally, in creating hybrid c-fos/ $\beta$-globin transcripts, we have been careful to minimize translational perturbations that could affect mRNA decay. For example, to avoid disrupting translation initiation signals (Kozak 1987), we have fused the c-fos and $\beta$ globin transcripts at sites downstream of the second codon. Furthermore, the chimeric transcripts examined in the present study have been designed to provide ribosomal coverage for all mRNA segments that normally are translated and to prevent translation of normally untranslated RNA segments.

The method described here for studying c-fos mRNA decay has additional features that deserve emphasis. The observation that the lifetime of c-fos mRNA is unnaturally prolonged in cells transfected with an excessive amount of c-fos DNA is crucial. It has led us to identify transient-transfection conditions under which wild-type c-fos mRNA produced from the transfected gene decays at the same rapid rate as the endogenous c-fos message. Furthermore, because fusion of the c-fos promoter to other transcription units allows transient synthesis of heterologous mRNA in response to serum addition /see below), it has been feasible to examine the decay of hybrid $\beta$-globin/c-fos messages under conditions identical to those employed for monitoring decay of the c-fos transcript itself. The strategy of swapping segments between the labile c-fos transcript and the stable $\beta$-globin message has permitted the identification of destabilizing determinants within c-fos mRNA that function in growth-factor-stimulated cells. This same approach should facilitate precise mapping of the sequence elements within the ARE and coding region that are essential for rapid degradation of the c-fos message. It should also allow identification of the determinants that render other growth-factor-inducible mRNAs unstable.

Studying c-fos mRNA decay in this manner requires that transcription end within minutes after growthfactor induction. Degradation of the c-fos message can then be monitored in the absence of further mRNA synthesis. Our experiments indicate that, as for the endogenous c-fos gene, heterologous gene transcription driven by the c-fos promoter is turned off shortly after growthfactor stimulation. This is indicated by nuclear run-on analysis of transcription of the BBB and BBF genes (V. Rivera and M.E. Greenberg, unpubl.) and by the finding that cytoplasmic accumulation of the $\mathrm{BBB}, \mathrm{BFB}, \mathrm{BBF}$, and $B B B+A R E$ transcripts ceases within $60 \mathrm{~min}$ after serum induction. Because the only c-fos element shared by all of these chimeras is the c-fos promoter, the c-fos gene segment located between 14 and $711 \mathrm{bp}$ upstream of the transcription initiation site must contain all of the cis-acting DNA sequence information necessary for stimulation and repression of transcription in response to growth factors. We conclude that in cells transfected with the BBB gene, the high level of $\beta$-globin mRNA present as late as $24 \mathrm{hr}$ after growth-factor stimulation reflects the very long lifetime of $\beta$-globin mRNA and not a loss of transcriptional repression.

The existence of two pathways for rapid degradation

Figure 7. Decay of BBF and BFB mRNA in cells treated with transcription inhibitors. NIH-3T3 cells were transiently transfected with pSV $\alpha$ l and either pBBF or pBFB. After serum stimulation for $30 \mathrm{~min}$, actinomycin $\mathrm{D}$ (top; $10 \mu \mathrm{g} / \mathrm{ml})$ or DRB (bottom; $30 \mu \mathrm{g} / \mathrm{ml})$ was added, and total cytoplasmic RNA was isolated at time intervals and analyzed by RNase protection and gel electrophoresis. (BBF) pT7BG-derived probe fragment protected by $B B F$ mRNA; $(B F B)$ pSP6BFB-derived probe fragment protected by BFB mRNA; (M) pSP6fos-derived probe fragment protected by mouse c-fos mRNA; (A) pSP6 $\alpha$ 133-derived probe fragment protected by $\alpha$-globin mRNA. Times correspond to minutes after serum stimulation. Beside each pair of autoradiograms is a semilogarithmic plot of the decay of $\mathrm{BBF}$ mRNA (dashed/dotted line) and BFB mRNA /solid line) in the presence of actinomycin D (top) or DRB (bottom). 
of c-fos mRNA could serve important biological functions. For example, certain extracellular signals might activate or inhibit one decay pathway but not the other. If so, these signals could cause dramatic half-life changes for transcripts bearing a single instability determinant, without significantly affecting the half-lives of messages able to decay by more than one pathway. This would allow a greater degree of flexibility in a cell's response to its environment or state of growth. Interestingly, precise deletion of either the ARE or a sequence near the $3^{\prime}$ end of the coding region appears to contribute to the oncogenic potential of the c-fos gene when it is expressed from a strong constitutive promoter (Meijlink et al. 1985). Because overexpression of the c-fos proto-oncogene can lead to oncogenesis, multiple degradation pathways may have evolved to ensure rapid turnover of c-fos mRNA in a variety of cell states.

\section{Materials and methods}

\section{Plasmid constructions}

DNA linkers were purchased from New England Biolabs. Oligonucleotides used for site-directed mutagenesis were synthesized using an Applied Biosystems $381 \mathrm{~A}$ instrument and purified by gel electrophoresis.

The $\alpha$-globin reference plasmid pSV $\alpha$ l was constructed by subcloning a $1.80-\mathrm{kb} B g l \mathrm{I}$ (filled in)-XbaI fragment from plasmid $\pi$ SVHPa 2 (Charnay et al. 1984), comprising the human al-globin gene driven by the SV40 early promoter and enhancer, between the PstI (filled in) and $\mathrm{XbaI}$ sites of plasmid pT7/T3 $\alpha-18$ (BRL).

Plasmid pF711 (Treisman 1985) contains a complete genomic copy of the human c-fos gene, beginning $0.71 \mathrm{~kb}$ upstream of the transcription initiation site and ending $1.60 \mathrm{~kb}$ beyond the polyadenylylation site.

Plasmid pF $\Delta 1$, a pF711 derivative, was constructed in several steps as follows. A $27-\mathrm{bp}$ BamHI-HindIII fragment was deleted from the polylinker region of $\mathrm{pF} 711$ to generate plasmid $\mathrm{pF} 99$. An NcoI site and a BamHI site were then introduced into pF99 at the promoter-proximal end of the c-fos ARE by oligonucleotide-directed mutagenesis (Nakamaye and Eckstein 1986) of a 4-bp segment located 623 bp downstream of the c-fos stop codon (CCATGAAAAC $\rightarrow$ CCATGGATCC). Simultaneous introduction of a point mutation 704 bp downstream of the c-fos stop codon (CTTGAG $\rightarrow$ CTCGAG) created an Xhol site at the promoter-distal end of the c-fos ARE and generated pF100. The 76-bp BamHI-Xhol fragment of pF100 was then excised, and the ends were filled in and religated to generate plasmid $\mathrm{pF} \Delta \mathrm{l}$.

Plasmid pF101 was created by linearizing pF100 with XhoI, removing the protruding 5 ' ends with mung bean nuclease, and inserting a Bglll linker (GGAGATCTCC) by the linker-tailing method (Lathe et al. 1984).

A nested set of deletions in the 3'-UTR of the human c-fos gene was constructed as follows. Bidirectional deletions were created from the BgIII site of pFl01 by exonuclease III/exonuclease VII (BRL) digestion followed by insertion of a BgIII linker (GGAGATCTCC). The complete c-fos gene segment downstream of the ARE was then reintroduced into the resulting plasmids by replacing the $B g I I I-E c o R I$ fragment containing the plasmid replication origin with the intact $3.34-\mathrm{kb} B g I I I-E c o R I$ fragment of $\mathrm{pF} 101$, to generate plamids $\mathrm{pF} \Delta 2-\mathrm{pF} \Delta 6$. End points were determined by analytical restriction enzyme digestions and agarose gel electrophoresis.

To generate plasmid pF $\Delta 7$, a $0.46-\mathrm{kb}$ HindIII fragment flanking the c-fos gene was first excised from plasmid pF4, and the ends were filled in and religated. A HindIII linker (CCCAAGCTTGGG) was then inserted between the BcII site and proximal Tthl11I site of the resulting plasmid by the linker-tailing methods.

Plasmids carrying hybrid genes with segments of the rabbit $\beta$-globin gene and the human c-fos gene were constructed in several steps as follows.

A 2.05-kb BglII fragment containing a complete copy of the genomic rabbit $\beta$-globin transcription unit was excised from plasmid pUK4.7 by partial BglII digestion and substituted for the $1.52-\mathrm{kb} B a m H I$ fragment of $\mathrm{pSV} \alpha 1$ to generate plasmid pSVB10. In pSVB10, the orientation of the $\beta$-globin gene was the same as that of the $\alpha$-globin gene that it replaced.

Plasmid pFFB was created by replacing the $1.28-\mathrm{kb} B g / \mathrm{II}-$ HindIII (filled in) fragment of pF $\Delta 6$ with a $0.44-\mathrm{kb} B g l I I-E c o R I$ (filled in) fragment of pSVB10 that contained the $3^{\prime}$-UTR of the rabbit $\alpha$-globin gene.

To generate plasmid pBBB, a 2.66-kb NarI (filled in)-BglII fragment of pFFB, extending from 13 bp upstream of the $c-f o s$ transcription initiation site to the $\beta$-globin/c-fos junction, was replaced with a $1.21-\mathrm{kb}$ PvuII-Bglil fragment of pSVB10, extending from $9 \mathrm{bp}$ upstream of the rabbit $\beta$-globin transcription initiation site to the end of the $\beta$-globin coding region.

Plasmid pBBB3 was generated by substituting a portion of the pUC18 polylinker region (KpnI-HindIII) for the $0.46-\mathrm{kb}$ KpnIHindill fragment downstream of the polyadenylylation site of pBBB.

Plasmid pBBB4 was generated by oligonucleotide-directed mutagenesis of $\mathrm{pBBB3}$, into which an MluI site was introduced by changing the sequence of the third and fourth $\beta$-globin codons from CATCTG to CACGCG.

Plasmid pF106 was constructed in several steps as follows. A 0.46-kb HindIII fragment was deleted from pF711, and a BgIII linker (GGAGATCTCC) was inserted into the NaeI site near the beginning of the c-fos 3'-UTR to generate plasmid pF104. A HincII site downstream of the c-fos polyadenylylation site in pF104 was destroyed by insertion of a HindIII linker (CCCAAGCTTGGG), and an MluI site was created by oligonucleotide-directed mutagenesis of the third, fourth, and fifth c-fos codons (TTCTCGGGC $\rightarrow$ TACGCGTGC), to generate plasmid pF106.

To construct plasmid pBBF, a 1.91-kb BglII-HindIII (filled in) fragment of pF104 was substituted for the $0.44-\mathrm{kb}$ BgIII-KpnI (filled in) fragment of pBBB. To construct plasmid pBFB, a 2.46kb MluI-BgIII fragment of pF106 was substituted for the 1.14kb MluI-BgllI fragment of pBBB4. To construct plasmid pFBB, a 263-bp BssHII-MluI fragment of pF106 was substituted for the 161-bp BssHII-Mlul fragment of pBBB4.

Plasmid $\mathrm{pBBF} \triangle \mathrm{ARE}$ is a deletion derivative of $\mathrm{pBBF}$ and was constructed from $\mathrm{pBBB} 3$ by replacing the $0.45-\mathrm{kb}$ BgIII (filledin)-HindIII fragment with the $2.34-\mathrm{kb} \mathrm{NaeI-HindIII}$ fragment of $\mathrm{pF} \Delta \mathrm{l}$.

The 83-bp BamHI-BglII fragment of pF101 encoding the c-fos ARE was subcloned into BglII-linearized $\mathrm{pBBB}$ to generate plasmid $\mathrm{pBBB}+\mathrm{ARE}$. The transcription orientation of the insert was the same as that in plasmid pF101.

Plasmids for generation of complementary-strand RNA probes were prepared as follows. Plasmid pT7BG was constructed by deleting a $1.17-\mathrm{kb}$ EcoRI-BamHI fragment from pSVB10. Plasmid pSP6BFB was constructed by inserting a 266bp NarI-HincII fragment of pBFB between the AccI and HindIII (filled in) sites of pGEM3 (Promega).

\section{Cell culture and transfection}

Mouse NIH-3T3 cells were passaged in Dulbecco's modified 
Eagle's medium (DMEM) with $10 \%$ calf serum. Cells were split to a density of $2 \times 10^{6} / 100-\mathrm{mm}$ dish $18 \mathrm{hr}$ before transfection by the calcium phosphate technique (Treisman 1985). Transfection mixtures contained $2-3 \mu \mathrm{g}$ of the test plasmid, $1 \mu \mathrm{g}$ of the internal control $\alpha$-globin plasmid (pSV $\alpha 1)$, and $17 \mu \mathrm{g}$ of carrier plasmid (pT7/T3 $\alpha-19$; BRL). After exposure to the plasmid precipitate for $12-16 \mathrm{hr}$, cells were serum-starved in DMEM $/ 0.5 \%$ calf serum for $26-30 \mathrm{hr}$ and then stimulated with DMEM $/ 15 \%$ fetal calf serum as described previously (Greenberg et al. 1987).

\section{Analysis of $m R N A$ decay}

Total cytoplasmic RNA was isolated at various times after serum stimulation, as described previously (Greenberg and Ziff 1984; Greenberg et al. 1986b). Transcripts derived from transfected DNA were detected by RNase protection analysis (Treisman 1985) of equal amounts of total cytoplasmic RNA, using complementary RNA probes. Human and mouse c-fos mRNA and certain derivatives thereof were detected with a 588-nucleotide RNA probe derived from EcoRI-linearized template plasmid pSP6fos (Treisman 1985). This probe is complementary to the 5 '-terminal segment of the human transcript and yields a protected fragment of 296 nucleotides or $65 \mathrm{nu}$ cleotides for human or mouse c-fos mRNA, respectively. Human $\alpha 1$-globin mRNA was detected with a 270 -nucleotide RNA probe that was derived from BamHI-linearized plasmid pSP6 133 (Charnay et al. 1984) and that hybridized to a 133nucleotide $\alpha$-globin mRNA segment within the first exon. Rabbit $\alpha$-globin mRNA and certain derivatives thereof were detected with a 200-nucleotide RNA probe that was derived from Ncol-linearized pT7BG and that hybridized to a 188 -nucleotide rabbit $\alpha$-globin mRNA segment within the second exon. BFB mRNA was detected with a 280 -nucleotide RNA probe that was derived from BamHI-linearized pSP6BFB and that hybridized to a 180-nucleotide BFB mRNA segment within the first exon.

To measure mRNA decay rates, data from autoradiograms were quantitated by densitometry on an LKB Ultroscan XL instrument. For each sample, the concentration of mRNA derived from the transfected c-fos gene or derivative thereof was normalized to the $\alpha$-globin mRNA internal standard. The concentration of endogenous mouse c-fos mRNA was normalized to the concentration of total cytoplasmic RNA. mRNA half-lives were then determined by least-squares analysis of semilogarithmic plots of normalized mRNA concentration as a function of time. Half-life errors were estimated from the standard deviation of the slope of each plot. Only data from samples isolated $\geqslant 60 \mathrm{~min}$ after serum stimulation were used to ensure that mRNA synthesis directed by the c-fos promoter had ceased.

\section{Acknowledgments}

We are grateful to Tony Imbalzano for constructing plasmid $\mathrm{pF} \Delta 7$, to Chyi-Ying Chen for helping with other plasmid constructions, and to Ross Hardison for providing us with a genomic clone of the rabbit $\beta$-globin gene. This research was supported by U.S. Public Health Service grants GM-35769 (to J.G.B.) and CA-43855 (to M.E.G.) from the National Institutes of Health. A.-B.S. is supported by a postdoctoral fellowship from the American Cancer Society, Massachusetts Division. M.E.G. is the recipient of an American Cancer Society Junior Faculty Research Award (JFRA-179) and is a Searle Scholar supported by the Chicago Community Trust. J.G.B. was supported by the Charles A. King Trust.

\section{References}

Almendral, J.M., D. Sommer, H. MacDonald-Bravo, J. Burckhardt, J. Perera, and R. Bravo. 1988. Complexity of the early genetic response to growth factors in mouse fibroblasts. Mol. Cell. Biol. 8: 2140-2148.

Belasco, J.G. and C.F. Higgins. 1988. Mechanism of mRNA decay in bacteria: A perspective. Gene 72: 15-24.

Brawerman, G. 1987. Determinants of messenger RNA stability. Cell 48: 5-6.

Charnay, P., R. Treisman, P. Mellon, M. Chao, R. Axel, and T. Maniatis. 1984. Differences in human $\alpha$ - and $\beta$-globin gene expression in mouse erythroleukemia cells: The role of intragenic sequences. Cell 38: 251-263.

Chiu, R., W.J. Boyle, J. Meek, T. Smeal, T. Hunter, and M. Karin. 1988. The c-Fos protein interacts with c-Jun/AP-1 to stimulate transcription of $\mathrm{AP}-1$ responsive genes. Cell 54: $541-552$.

Cochran, B.H., J. Zullo, I.M. Verma, and C.D. Stiles. 1984. Expression of the c-fos gene and a c-fos-related gene is stimulated by platelet-derived growth factor. Science 226: 10801082.

Curran, T. and J.I. Morgan. 1985. Superinduction of the fos gene by nerve growth factor in the presence of peripherally active benzodiazepines. Science 229: 1265-1268.

- 1986. Barium modulates c-fos expression and posttranslational modification. Proc. Natl. Acad. Sci. 83: 85218524.

Fort, P., J. Rech, A. Vie, M. Piechaczyk, A. Bonnieu, P. Jeanteur, and J.-M. Blanchard. 1987. Regulation of c-fos gene expression in hamster fibroblasts: Initiation and elongation of transcription and mRNA degradation. Nucleic Acids Res. 15: $5657-5667$.

Greenberg, M.E. and E.B. Ziff. 1984. Stimulation of 3T3 cells induces transcription of the c-fos proto-oncogene. Nature 311: 433-438.

Greenberg, M.E., Z. Siegfried, and E.B. Ziff. 1987. Mutation of the c-fos dyad symmetry element inhibits serum inducibility in vivo and nuclear regulatory factor binding in vitro. Mol. Cell. Biol. 7: 1217-1225.

Greenberg, M.E., A.L. Hermanowski, and E.B. Ziff. 1986a. Effects of protein synthesis inhibitors on growth factor activation of c-fos, c-myc, and actin gene transcription. Mol. Cell. Biol. 6: 1050-1057.

Greenberg, M.E., E.B. Ziff, and L.A. Greene. 1986b. Stimulation of neuronal acetylcholine receptors induces rapid gene transcription. Science 234: 80-83.

Greenberg, M.E., L.A. Greene, and E.B. Ziff. 1985. Nerve growth factor and epidermal growth factor induce transient changes in proto-oncogene transcription in $\mathrm{PC} 12$ cells. $J$. Biol. Chem. 260: 14101-14110.

Jenuwein, T. and R. Muller. 1987. Structure-function analysis of fos protein: A single amino acid change activates the immortalizing potential of v-fos. Cell 48: 647-657.

Kabnick, K.S. and D.E. Housman. 1988. Determinants that contribute to cytoplasmic stability of human c-fos and $\beta$-globin mRNAs are located at several sites in each mRNA. Mol. Cell. Biol. 8: 3244-3250.

Kozak, M. 1987. At least six nucleotides preceding the AUG initiator codon enhance translation in mammalian cells. $J$. Mol. Biol. 196: 947-950.

Krowczynska, A., R. Yenofsky, and G. Brawerman. 1985. Regulation of messenger RNA stability in mouse erythroleukemia cells. I. Mol. Biol. 181: 231-239.

Kruijer, W., J.A. Cooper, T. Hunter, and I.M. Verma. 1984. Platelet-derived growth factor induces rapid but transient 
expression of the c-fos gene and protein. Nature 312: $711-$ 716.

Lathe, R., M.P. Kieny, S. Skory, and J.P. Lecocq. 1984. Linkertailing: Unphosphorylated linker oligonucleotides for joining DNA termini. DNA 3: 173-182.

Lau, L.F. and D. Nathans. 1985. Identification of a set of genes expressed during the G0/Gl transition of cultured mouse cells. $E M B O$ I. 4: 3145-3151.

Lim, R.W., B.C. Varnum, and H.R. Herschman. 1987. Cloning of tetradecanoyl phorbol ester-induced 'primary response' sequences and their expression in density-arrested Swiss 3T3 cells and a TPA non-proliferative variant. Oncogene 1: $263-270$.

Maderious, A. and S. Chen-Kiang. 1984. Pausing and premature termination of human RNA polymerase II during transcription of adenovirus in vivo and in vitro. Proc. Natl. Acad. Sci. 81: $5931-5935$.

Meijlink, F., T. Curran, A.D. Miller, and I.M. Verma. 1985. Removal of a 67-base-pair sequence in the noncoding region of proto-oncogene fos converts it to a transforming gene. Proc. Natl. Acad. Sci. 82: 4987-4991.

Miller, A.D., T. Curran, and I.M. Verma. 1984. c-fos protein can induce cellular transformation: A novel mechanism of activation of a cellular oncogene. Cell 36: 51-60.

Muller, R., R. Bravo, J. Burckhardt, and T. Curran. 1984. Induction of $\mathrm{c}$-fos gene and protein by growth factors precedes activation of c-myc. Nature 312: 716-720.

Mullner, E.W. and L.C. Kuhn. 1988. A stem-loop in the 3 ' untranslated region mediates iron-dependent regulation of transferrin receptor mRNA stability in the cytoplasm. Cell 53: $815-825$.

Nakamaye, K.L. and F. Eckstein. 1986. Inhibition of restriction endonuclease $\mathrm{NciI}$ cleavage by phosphorothioate groups and its application to oligonucleotide-directed mutagenesis. $\mathrm{Nu}$ cleic Acids Res. 14: 9679-9698.

Rahmsdorf, H.J., A. Schonthal, P. Angel, M. Litfin, U. Ruther, and P. Herrlich. 1987. Post-transcriptional regulation of c-fos mRNA expression. Nucleic Acids Res. 15: 1643-1660.

Rauscher, F.J., D.R. Cohen, T. Curran, T.J. Bos, P.K. Vogt, D. Bohmann, R. Tiian, and B.R. Franza, Jr. 1988. fos-associated protein $\mathrm{p} 39$ is the product of the iun proto-oncogene. Science 240: 1010-1016.

Sassone-Corsi, P., W.W. Lamph, M. Kamps, and I.M. Verma. 1988. fos-associated cellular p39 is related to nuclear transcription factor AP-1. Cell 54: 553-560.

Shaw, G. and R. Kamen. 1986. A conserved AU sequence from the $3^{\prime}$ untranslated region of GM-CSF mRNA mediates selective mRNA degradation. Cell 46: 659-667.

Treisman, R. 1985. Transient accumulation of c-fos RNA following serum stimulation requires a conserved $5^{\prime}$ element and c-fos $3^{\prime}$ sequence. Cell 42: 889-902.

van Straaten, F., R. Muller, T. Curran, C. van Beveren, and I.M. Verma. 1983. Complete nucleotide sequence of a human c-onc gene: Deduced amino acid sequence of the human c-fos protein. Proc. Natl. Acad. Sci. 80: 3183-3187.

Zandomeni, R., B. Mittleman, D. Bunick, S. Ackerman, and R. Weinmann. 1982. Mechanism of action of dichloro- $\beta$-D-ribofuranosylbenzimidazole: Effect on in vitro transcription. Proc. Natl. Acad. Sci. 79: 3167-3170. 


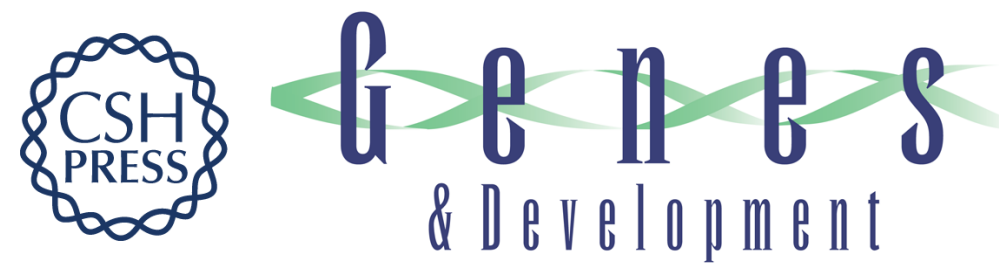

\section{The c-fos transcript is targeted for rapid decay by two distinct mRNA degradation pathways.}

A B Shyu, M E Greenberg and J G Belasco

Genes Dev. 1989, 3:

Access the most recent version at doi:10.1101/gad.3.1.60

References This article cites 35 articles, 14 of which can be accessed free at:

http://genesdev.cshlp.org/content/3/1/60.full.html\#ref-list-1

License

Email Alerting

Service

Receive free email alerts when new articles cite this article - sign up in the box at the top right corner of the article or click here.

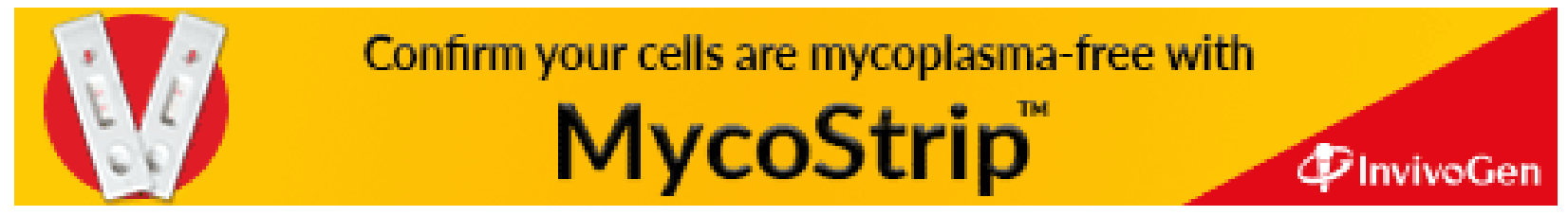

